\title{
Effects of sample-specific ratios on free-choice matching-order sequences
}

\author{
RICHARD PISACRETA and JEFFREY RAUTIO \\ Ferris State College, Big Rapids, Michigan
}

\begin{abstract}
During Experiment 1, three pigeons were trained on a matching-to-sample task with yellow, white, and blue stimuli. Each matching-to-sample trial was presented on the three upper, middle, or lower horizontal keys of a nine-key response panel. After acquisition, each of the three center-column keys simultaneously presented a different sample. The pigeon could match each sample in any order. Each bird developed dominant matching-order sequences. Later, the birds matched familiar samples, before matching a novel sample, during $68 \%-90 \%$ of the trials. In Experiment 2, different sample-specific ratios were employed. Each bird matched the sample with the lowest ratio first.
\end{abstract}

The zero-delay matching-to-sample (MTS) procedure is often employed to study complex discrimination learning, short-term memory, and acquisition of conceptual behavior in nonhumans (e.g., Cumming \& Berryman, 1965; Cumming, Berryman, \& Cohen, 1965; D'Amato, 1973; Grant, 1975; Roberts \& Grant, 1976; Santi, Grossi, \& Gibson, 1982; Winograd, 1971). The procedure presents a pigeon with a sample stimulus projected onto the center key of a three-key response panel. A response on the sample extinguishes it and produces a different comparison (CO) stimulus on each of the two side keys. A response on the $\mathrm{CO}$ stimulus that matches the sample produces a reinforcer, an intertrial interval (ITI), and the next trial. An incorrect response, a peck to the nonmatching $\mathrm{CO}$ stimulus, yields a brief blackout followed by the next trial.

One common feature of almost every MTS experiment is the presentation of one sample stimulus per trial. However, given the opportunity, pigeons will demonstrate matching preferences. Pisacreta (1982a) presented pigeons with two pairs of matching stimuli, for example, two red and two green keys. The birds' task was to peck the keys in a matching sequence, that is, to peck each of the red keys and then the two green keys, or vice versa. The data indicated that the birds reliably matched green before red. During later trials, they reliably pecked hues (yellow or blue) before forms (circle, X, horizontal line, or vertical line).

Experiment 1 combined the MTS paradigm with the free-choice matching option present in Pisacreta (1982a). This was accomplished by presenting each bird with three sample stimuli at trial onset. The bird had to

This work was supported by a Ferris Faculty Research grant to the first author. J. Rautio is with the School of Optometry, Ferris State College. Reprints can be obtained from R. Pisacreta, Psychology Department, Ferris State College, Big Rapids, MI 49807. match each sample, but it could choose the order in which it matched the samples.

\section{EXPERIMENT 1}

\section{Method}

\section{Subjects}

Three white Carneaux pigeons, maintained at $80 \%$ of their free-feeding weights, were employed. Each bird had had training on a discrimination task but was unfamiliar with the stimuli and procedures used here.

\section{Apparatus}

The apparatus was a $35 \times 35 \times 37 \mathrm{~cm}$ operant chamber enclosed in a sound-attenuating hull. Figure 1 shows the response panel. The response panel measured $37 \times 35 \mathrm{~cm}$. Each key was $2.7 \mathrm{~cm}$ in diameter. Stimuli were rear-projected by IEE inline projectors. The horizontal and vertical distances between the keys were 8.1 and $6.4 \mathrm{~cm}$, respectively, center to center. The feeder (located $10 \mathrm{~cm}$ above the floor) provided 3-sec access to grain. The houselight was on before and after sessions. During sessions, only the keys and feeder provided light. White noise masked extraneous noise. An E and L Instruments MMD-1 computer recorded data and controlled experimental events.

\section{Procedure}

Phase 1-Acquisition. Each bird was initially trained on a standard one-sample MTS procedure. During each trial, the upper level keys $(1,2,3)$, the middle keys $(4,5,6)$, or the lower keys $(7,8,9)$ presented a standard MTS problem. Three hues-yellow, blue, and white-were employed. At trial onset, one of the three center-column keys $(2,5$, or 8 ) presented the sample stimulus. Five responses (FR5) to the sample extinguished it and produced the comparison stimuli on the horizontally adjacent side keys. A response to the matching comparison key produced grain, a 3-sec ITI, and the next trial. A response to the nonmatching key eliminated the comparison stimuli and relighted the sample key. This correction procedure allowed a trial to be indefinitely repeated. A new trial started only after a correct match. Each session consisted of 36 reinforcers. Counterbalancing provided 12 reinforcers on each of the three levels and hues, as well as six reinforcers to each of the six side keys. Each bird was provided three daily sessions until its errorless 


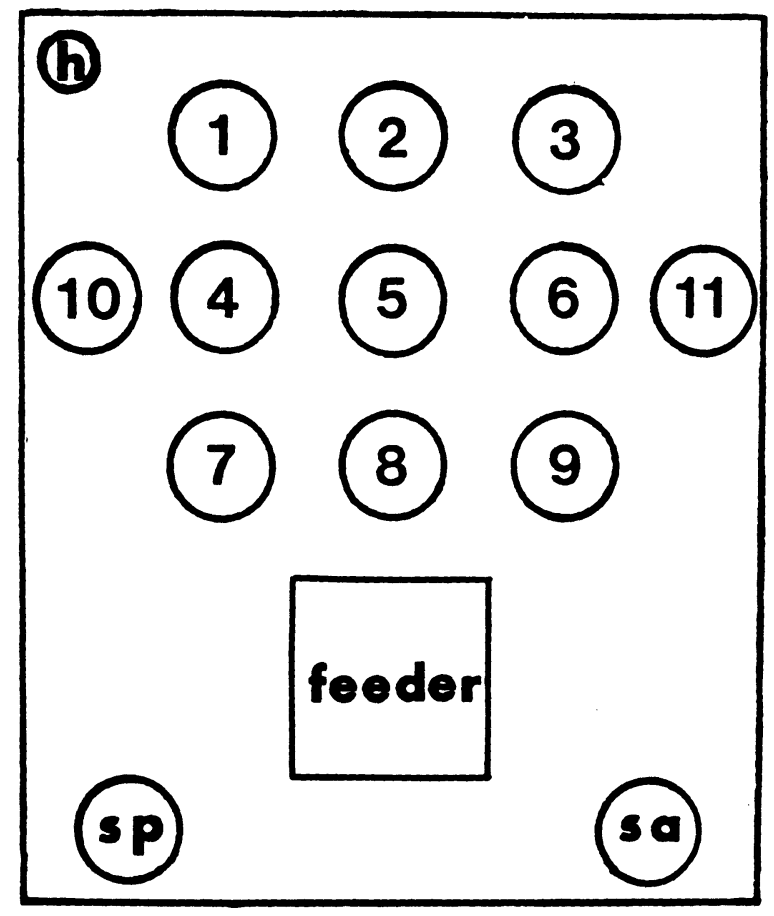

Figure 1. The response panel used. The keys are numbered 1-11. "Sp" and " $H$ " represent the speaker and the houselight, respectively.

performance had surpassed $70 \%$ for at least five sessions. Phase 1 lasted 60 sessions.

Phase 2-Free-choice matching to sample. At trial onset, Keys 2, 5, and 8 presented a different sample stimulus. A response to any sample extinguished the other two available samples. Four more responses (FR5) eliminated the sample and produced the comparison stimuli on the horizontally adjacent side keys. A response to the matching comparison key produced a reinforcer, an ITI, and the reillumination of the remaining two samples. A response to the nonmatching key eliminated the comparison stimuli and reproduced all three samples. After two successful matches, only the third sample was presented. If an error (mismatch) occurred after a successful match, only the two unmatched samples reappeared. Likewise, if a mismatch occurred after two successful matches, only the third sample was repeated until it was correctly matched. Although each bird had to successfully match each of the three samples, it could determine the order in which the matches would occur. Sessions terminated after 36 reinforcers. Phase 2 lasted 30 sessions.

Phase 3-Novel stimulus. For the next 15 sessions, a white vertical line projected onto a black background replaced the white stimulus on all trials. It was presented as a sample and as a correct and an incorrect $\mathrm{CO}$ stimulus. Therefore, the concurrently available samples were two hues (yellow and blue) and one form (white vertical line).

\section{Results}

Figure 2 shows the percentage of correct matches produced during each phase. These values were derived by dividing the number of errorless matching trials by 36 and multiplying the result by 100 . The figure shows that, during Phase 1, the birds required 21-40 sessions to surpass $70 \%$ accuracy. Although three sample keys and six comparison keys were employed during Phase 1, the acquisition curves generated by each bird are comparable to those reported by other researchers (e.g., Farthing \& Opuda, 1974; Lydersen, Perkins, \& Chairez, 1977). During the last five sessions, Birds B1, B2, and B3 produced an average of 7,10 , and 3 errors per session, respectively. The simultaneous availability of three samples during Phase 2 initially reduced the matching accuracies of Birds B2 and B3. Closer analysis revealed that errors were distributed evenly across all side keys, levels, and comparison stimuli. Birds B1, B2, and B3 averaged 5,6 , and 2 errors per session, respectively, during the last five sessions. The introduction of the novel form (Phase 3) produced an initial 10\%-40\% reduction in matching accuracy. Most of the errors occurred during form-matching trials in which the birds pecked incorrect comparison hues.

During Phases 2 and 3, each bird had the opportunity to emit particular stimulus-matching-order (e.g., yellowblue-white or blue-yellow-white) or particular samplekey-order (e.g., 2-5-8, 5-8-2, etc.) preferences. Six stimulus-order and six key-order sequences were possible. During Phase 2, Birds B1 and B2 matched the samples in the sample-key orders 8-5-2 and 5-8-2 during 60\% and $86 \%$ of the trials, respectively. Bird B3 matched in the key order 8-5-2 during 98\% of the trials. During Phase 3, each bird switched to the same sample-order sequences, frequently matching the vertical-line sample last. Birds B1, B2, and B3 emitted matching sequences blueyellow-vertical and yellow-blue-vertical on $68 \%, 89 \%$, and $72 \%$ of the trials, respectively. As the birds acquired matching the vertical line, variation increased and the dominant key-order sequences of Phase 2 emerged.

\section{Discussion}

The data show that pigeons can efficiently acquire matchingto-sample performances presented on three sets of horizontal keys. Each bird produced specific key-order sequences during Phase 2. Pisacreta (1982b) demonstrated that, when given the opportunity to peck six to nine keys in any sequence to obtain reinforcement, birds would develop particular response sequences that were emitted during the majority of the trials. During Phase 2 of Experiment 1, each bird developed particular

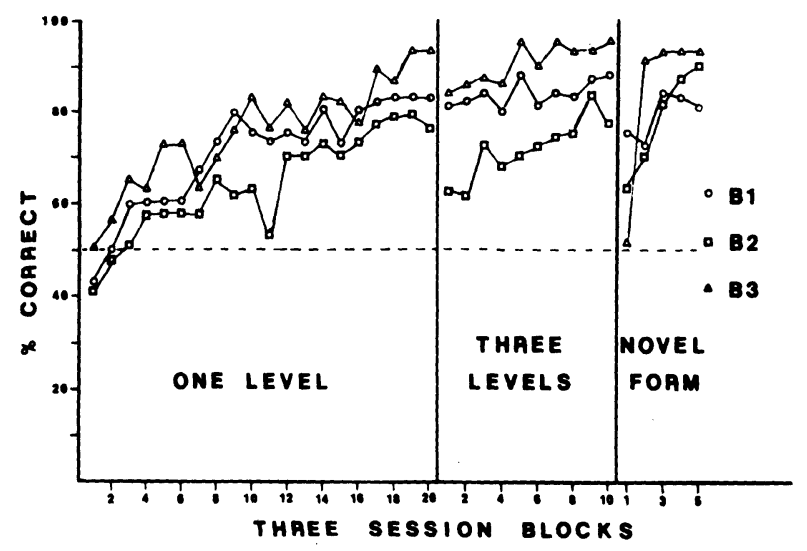

Figure 2. Percentage of correct matches generated during each three-session block of Experiment 1. 
key-order sequences. Apparently, the reinforcers strengthened these key sequences, perhaps superstitiously, in addition to specific matches.

During Phase 3, each bird often avoided the form sample stimulus until that stimulus was the only one present; that is, the bird matched the blue and yellow samples first. Pisacreta (1982a) also reported that pigeons will avoid novel samples. In MTS, pigeons have often pecked an incorrect familiar CO stimulus instead of a correct novel CO stimulus (Carter \& Werner, 1978). Presumably, the birds peck familiar stimuli because they have a reinforcement history of doing so. There may also be aversive aspects of a novel stimulus resulting from its initial association with delayed reinforcement (due to errors). Either of these factors would predict the sample-order preferences generated in Phase 3.

\section{EXPERIMENT 2}

Experiment 1 paired a FR5 requirement with each sample. Several studies have demonstrated that matching accuracy increases with higher sample ratios (Lydersen et al., 1977; Roberts \& Grant, 1976; Sacks, Kamil, \& Mack, 1972). Urcuioli and Honig (1980) suggested that the influence of exteroceptive sample cues is overshadowed by sample-specific schedule requirements. Paul (1983) provided supportive data by employing specific sample ratios in a symbolic MTS task. Experiment 2 paired a different ratio with each sample in an attempt to: (1) improve the matching levels established in Experiment 1, (2) determine if sample-specific ratios would alter matching-order sequences, and (3) improve transfer to other novel stimuli.

\section{Method}

\section{Subjects and Apparatus}

The subjects and the apparatus were the same as those in Experiment 1.

\section{Procedure}

Phases 1-8. The matching conditions of Experiment 1, Phase 3, were in effect. The sample ratios were FR5 for the vertical line and FR10 for the yellow and blue samples. Phase 1 (and subsequent phases) lasted 15 sessions each. Phase 2 paired a FR15 requirement with the blue and yellow samples. Phase 3 again paired a FR5 schedule with the blue, yellow, and white vertical line samples. Phase 4 reemployed the blue, yellow, and white hue samples, each with a FR5 requirement. Phase 5 presented white, yellow, and a novel white triangle, projected on to a black background, as stimuli. Phase 6 paired FR5, FR10, and FR15 schedules with the triangle, yellow sample, and white sample, respectively. Phase 7 paired FR2, FR10, and FR20 schedules with the triangle, yellow sample, and white sample, respectively. Finally, Phase 8 paired a FR5 schedule with each sample.

\section{Results}

Figure 3 depicts percentage of correct matches. The first panel (Phase 1) shows that increasing the response requirement to FR10 for blue and yellow samples did not affect matching performance. Introduction of the FR15 sample ratio in Phase 2 slightly elevated each bird's matching level. Pairing a FR5 with each sample in Phase 3 yielded a slight reduction in matching accuracy

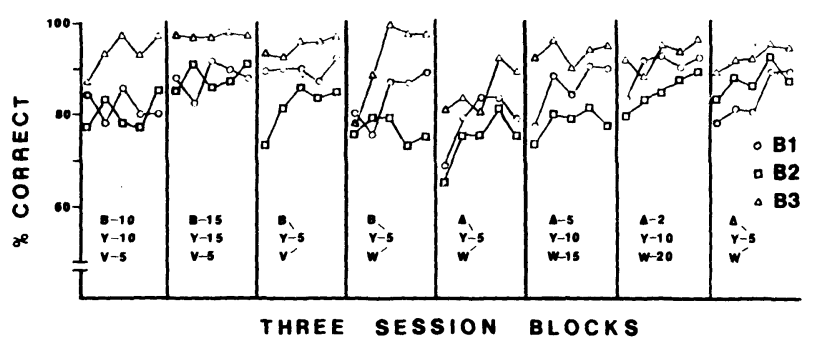

Figure 3. Percentage of correct matches produced during Experiment 2. Stimuli included: B(lue), Y(ellow), V(ertical), W(hite), and triangle. The letters and numbers below each panel indicate the samples and ratios, respectively.

for Birds B2 and B3. Replacing the vertical line with the familiar white hue stimulus (in Phase 4) initially produced $10 \%$ and $20 \%$ reduction in matching accuracies for Birds B1 and B3, respectively. A 10\% matching reduction persisted in Bird B3. Introducing the triangle in Phase 5 lowered matching levels in all birds. Pairing a different ratio with each sample in Phases 6 and 7 improved matching performances. Equalization of sample ratios in Phase 8 reduced the matching accuracy of each bird. As in Experiment 1, errors were distributed evenly among all six side keys. During Phase 5 , in which the triangle was introduced, errors seldom occurred when the triangle was the incorrect $\mathrm{CO}$ stimulus. When the triangle was the sample, however, all birds frequently pecked the yellow or white incorrect $\mathrm{CO}$ stimulus. Birds frequently peck incorrect familiar stimuli when the alternate is a novel stimulus (Carter \& Werner, 1978; Farthing \& Opuda, 1974). When the triangle was paired with the lowest ratios, in Phases 6 and 7 , each bird frequently pecked it when it was the incorrect comparison stimuli. Similar results have been reported by Lydersen and Perkins (1974) and Ruhl and Paul (1978), who also demonstrated that pigeons will develop a preference for a $\mathrm{CO}$ stimulus that, when presented as a sample, is paired with the lowest sample-ratio requirement. Table 1 displays how the differential sample ratios affected each bird's matching-order preferences. Each bird produced a combination of stimulus-matchingorder and key-order preference during Phase 1 . The five additional responses (FR10) required with blue and yellow samples relative to the FR5 assigned to the vertical line were enough to occasion matching the vertical line first. Pairing (during Phase 2) FR15, FR10, and FR5 with the blue, yellow, and vertical samples, respectively, eliminated key-order preference and left matching the vertical line sample prepotent. With equal sample ratios in Phase 3, matching the vertical line first persevered, but key-order matching preferences reemerged. The key-order matching preferences maintained during Phase 4 were similar to those generated in Phase 2 of Experiment 1. The tendency of Birds B1 and B2 to match white samples first may have represented a generalization effect from matching the white form sample in an earlier phase. The introduction of the novel triangle stimulus in Phase 5 yielded a shift to key-order preferences. During Phases 6 and 7, each bird predom- 
Table 1

Dominant Key-Order and Stimulus-Order Sequences

\begin{tabular}{|c|c|c|c|c|c|c|c|}
\hline \multirow[b]{2}{*}{ Phas } & \multirow{2}{*}{$\begin{array}{c}\text { Sample and } \\
\text { Ratios }\end{array}$} & \multicolumn{2}{|l|}{ B1 } & \multicolumn{2}{|l|}{ B2 } & \multicolumn{2}{|l|}{ B3 } \\
\hline & & Order & $\%$ & Order & $\%$ & Order & $\%$ \\
\hline 1 & $\mathrm{~V}-5, \mathrm{Y}-10, \mathrm{~B}-10$ & $\begin{array}{l}\text { V-Y-B } \\
\text { V-B-Y } \\
8-5-2\end{array}$ & $\begin{array}{l}43 \\
24 \\
29\end{array}$ & $\begin{array}{l}\text { V-Y-B } \\
\text { Y-V-B } \\
2-5-8\end{array}$ & $\begin{array}{l}34 \\
22 \\
45\end{array}$ & $\begin{array}{l}\text { V-Y-B } \\
\text { Y-V-B } \\
8-5-2\end{array}$ & $\begin{array}{l}22 \\
30 \\
63\end{array}$ \\
\hline 2 & $\mathrm{~V}-5, \mathrm{Y}-15, \mathrm{~B}-15$ & & $\begin{array}{l}52 \\
45\end{array}$ & & $\begin{array}{l}53 \\
46\end{array}$ & $\begin{array}{l}\text { V-Y-B } \\
\text { V-B-Y }\end{array}$ & $\begin{array}{l}48 \\
51\end{array}$ \\
\hline 3 & $\mathrm{~V}-5, \mathrm{Y}-5, \mathrm{~B}-5$ & $\begin{array}{c}\text { V-Y-B } \\
\text { V-B-Y } \\
5-8-2\end{array}$ & $\begin{array}{l}31 \\
44 \\
36\end{array}$ & $\begin{array}{c}\text { V-Y-B } \\
\text { V-B-Y } \\
2-5-8\end{array}$ & $\begin{array}{l}53 \\
27 \\
28\end{array}$ & $\begin{array}{l}\text { V-Y-B } \\
\text { V-B-Y } \\
8-5-2\end{array}$ & $\begin{array}{l}22 \\
32 \\
64\end{array}$ \\
\hline 4 & W-5, Y-5, B-5 & $\begin{array}{c}\text { W-Y-B } \\
\text { W-B-Y } \\
5-8-2\end{array}$ & $\begin{array}{l}32 \\
29 \\
32\end{array}$ & $\begin{array}{c}\text { W-Y-B } \\
\text { W-B-Y } \\
2-5-8\end{array}$ & $\begin{array}{l}42 \\
23 \\
41\end{array}$ & $\begin{array}{c}\text { B-W-Y } \\
8-5-2 \\
8-2-5\end{array}$ & $\begin{array}{l}24 \\
59 \\
28\end{array}$ \\
\hline 5 & $\mathrm{~T}-5, \mathrm{Y}-5, \mathrm{~W}-5$ & $\begin{array}{l}8-5-2 \\
5-8-2\end{array}$ & $\begin{array}{l}67 \\
27\end{array}$ & $\begin{array}{l}2-5-8 \\
\text { T-Y-W } \\
W-Y-T\end{array}$ & $\begin{array}{l}58 \\
27 \\
31\end{array}$ & $8-5-2$ & 86 \\
\hline 67 & $\mathrm{~T}-5, \mathrm{Y}-10, \mathrm{~W}-15$ & $\begin{array}{c}\text { T-W-Y } \\
8-5-2 \\
5-8-2\end{array}$ & $\begin{array}{l}44 \\
28 \\
37\end{array}$ & $\begin{array}{c}T-W-Y \\
2-5-8\end{array}$ & $\begin{array}{l}39 \\
41\end{array}$ & $\begin{array}{c}T-Y-W \\
8-5-2 \\
8-2-5\end{array}$ & $\begin{array}{l}34 \\
42 \\
34\end{array}$ \\
\hline 7 & $\mathrm{~T}-2, \mathrm{Y}-10, \mathrm{~W}-20$ & $\mathrm{~T}-\mathrm{Y}-\mathrm{W}$ & 72 & $T-Y-W$ & 70 & $\mathrm{~T}-\mathrm{Y}-\mathrm{W}$ & 74 \\
\hline 8 & $\mathrm{~T}-5, \mathrm{Y}-5, \mathrm{~W}-5$ & $\begin{array}{l}8-5-2 \\
T-Y-W\end{array}$ & $\begin{array}{l}56 \\
36\end{array}$ & $\begin{array}{l}\text { T-Y-W } \\
2-5-8\end{array}$ & $\begin{array}{l}52 \\
34\end{array}$ & $\begin{array}{l}T-Y-W \\
8-5-2\end{array}$ & $\begin{array}{l}42 \\
34\end{array}$ \\
\hline
\end{tabular}

Note-Dominant sequences were generated during Phases 1-8, inclusive. The samples included: B(lue), Y(ellow), W(hite), $V($ ertical line), and $T$ (riangle).

inantly matched the sample in the sequence: (1) lowest ratio sample, (2) middle ratio sample, (3) highest ratio sample. Finally, equalization of sample ratios in Phase 8 was accompanied by both perseverence of the matching sequence triangle-yellow-white and another return of key-order preferences.

\section{Discussion}

Employing different sample-specific ratios did not greatly improve MTS performance. However, Cohen, Looney, Brady, and Aucella (1976) and Urcuioli and Honig (1980), among others, have employed sample-specific schedules during acquisition sessions. In the present study, MTS control had already been established by the sample hue or form stimulus dimension. The later introduction of a redundant (with respect to the sample stimulus) ratio stimulus dimension may limit the degree of control these sample-specific schedules eventually exert. The decreases in matching accuracy during Phase 8 (equal sample ratios) relative to the matching levels maintained during Phases 6 and 7 (different sample-specific ratios), however, implies that the sample ratios did contribute somewhat to the overall matching performances. Although the sample-specific ratios did not come to overshadow the hue or form sample stimulus dimension to the degree shown by Paul (1983) and Urcuioli and Honig (1980), these ratios did produce changes in the order in which the birds responded to sample stimuli.

Finally, in terms of MTS sequences, the data indicate that: (1) when presented with two familiar and one novel sample, pigeons match the novel sample last; and (2) when a different ratio is required on each sample, the birds first match the sample with the lowest ratio requirement, then the middle ratio sample, and, finally, the sample with the highest ratio.

\section{REFERENCES}

Carter, D. E., \& Werner, T. J. (1978). Complex learning and information processing by pigeons: A critical analysis. Journal of the Experimental Analysis of Behavior, 29, 565-601.

Cohen, L. R., Looney, T. A., Brady, J. H., \& Aucella, A. F. (1976). Differential sample response schedules in the acquisition of conditional discriminations by pigeons. Journal of the Experimental Analysis of Behavior, 26, 301-314.

Cumming, W. W., \& Berryman, R. (1965). The complex discriminated operant: Studies of matching-to-sample and related problems. In D. I. Mostofsky (Ed.), Stimulus generalization. (pp. 284-330). Stanford, CA: Stanford University Press.

Cumming, W. W., Berryman, R., \& Cohen, L. R. (1965). Acquisition and transfer of zero-delay matching. Psychological Reports, 17, 435-445.

D'Aмato, M. R. (1973). Delayed matching and short-term memory in monkeys. In G. H. Bower (Ed.), The psychology of learning and motivation: Advances in research and theory (Vol. 7, pp. 227-269). New York: Academic Press.

Farthing, G. W., \& OPUDA, M. J. (1974). Transfer of matchingto-sample in pigeons. Journal of the Experimental Analysis of Behavior, 21, 199-213.

Grant, D. S. (1975). Proactive interference in pigeon short-term memory. Journal of Experimental Psychology: Animal Behavior Processes, 2, 1-16.

Lydersen, T., \& Perkins, D. (1974). Effects of responseproduced stimuli upon conditional discrimination performance. Journal of the Experimental Analysis of Behavior, 21, 307-334.

Lydersen, T., Perins, D., \& Chairez, H. (1977). Effects of fixed ratio sample and choice response requirements upon oddity matching. Journal of the Experimental Analysis of Behavior, 27, 97-101.

PAUL, C. (1983). Ratio effects in matching-to-sample. Journal of the Experimental Analysis of Behavior, 39, 77-85.

Pisacreta, R. (1982a). Concurrent sequential matching in the pigeon. Bulletin of the Psychonomic Society, 20, 183-186.

Pisacreta, R. (1982b). Some factors that influence the acquisition of complex, stereotyped response sequences in pigeons. Journal of the Experimental Analysis of Behavior, 37, 359-369.

Roberts, W. A., \& Grant, D. S. (1976). Studies of short-term memory in the pigeon using the delayed matching-to-sample procedure. In D. I. Medin, W. A. Roberts, \& R. T. David (Eds.), Processes of animal memory. (pp. 79-112). Hillsdale, NJ: Erlbaum.

RuHL, V., \& PAUL, C. (1978, April). The effect of fixed ratio sample requirements on the acquisition of matching-to-sample in pigeons. Paper presented at the meeting of the Eastern Psychological Association, Washington, D.C.

SACKs, R. A., KAMIL, A. C., \& MACK, R. (1972). The effects of fixed ratio sample requirements on matching-to-sample in the pigeon. Psychonomic Science, 26, 291-293.

Santi, A., Grossi, V., \& Gibson, M. (1982). Differences in matching-to-sample performance with element and compound sample stimuli in pigeons. Learning and Motivation, 13, 240-256.

Urcuioli, P. J., \& Honig, W. K. (1980). Control of choice in conditional discriminations by sample-specific behaviors. Journal of Experimental Psychology: Animal Behavior Processes, 6, 251-277.

Winograd, E. (1971). Some issues relating animal memory to human memory. In W. K. Honig \& P. H. R. James (Eds.), Animal memory (pp. 259-278). New York: Academic Press.

(Manuscript received for publication January 6, 1984.) 